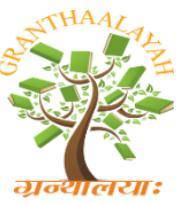
\author{
GRANTHAALAYAH \\ A knowledge Repository
}

INTERNATIONAL JOURNAL OF RESEARCH -

Science

\title{
CONSUMPTION OF SATURATED ANIMAL FATS IN THE DIET OF HUMANS MAY DECREASE THE RATE OF HEART DISEASE IN THE FUTURE
}

\author{
Somayeh Zaminpira ${ }^{* 1}$, Sorush Niknamian ${ }^{2}$ \\ ${ }^{* 1}$ Ph.D. in Cellular and Molecular Biology, University of Cambridge, United Kingdom \\ ${ }^{2}$ Ph.D. in Cellular and Molecular Biology, University of Cambridge, United Kingdom
}

DOI: https://doi.org/10.29121/granthaalayah.v5.i1.2017.1904

\begin{abstract}
Fats, as part of the human dietary regime are a concentrated source of energy. Animals contain saturated and plants contain unsaturated type of fatty acids. In this prospective research, the role of animal saturated fatty acids is highlighted and is proven to be a rational dietary source for the human diet. Saturated fats consumption is a wise choice in order to reduce the coronary heart disease risk, although it is believed in an opposite way. Researching through the healthiest tribes and knowing the biological function of saturated fats, and considering that eukaryotic cells need saturated fats to function properly, made this research important to conclude the rational dietary choice of edible fats and oils.
\end{abstract}

Keywords: Saturated Fat; Coronary Heart Disease; Healthiest Tribes.

Cite This Article: Somayeh Zaminpira, and Sorush Niknamian. (2017). "CONSUMPTION OF SATURATED ANIMAL FATS IN THE DIET OF HUMANS MAY DECREASE THE RATE OF HEART DISEASE IN THE FUTURE." International Journal of Research - Granthaalayah, 5(1), 295-303. https://doi.org/10.29121/granthaalayah.v5.i1.2017.1904.

\section{Introduction}

Saturated fatty acids (SFA), are compounds that contain a carboxylic acid group with a long hydro-carbon chain consisting of carbon and hydrogen atoms. A carboxylic acid is a compound that contains a carboxyl group. Saturated fatty acids lack double bonds. Therefore, they are saturated with hydrogen for double bonds which decrease the number of hydrogen on each carbon. Since saturated fatty acids have merely single bonds, each carbon atom inside the chain has two hydrogen atoms, except for the omega carbon at the end that has three hydrogens. In human diet, the most eaten saturated fatty acids are myristic, palmitic and stearic acids. ${ }^{1}$ Types of saturated fatty acids are shown in table below: 
Table1: Saturated fatty acids names and chemical formula.

\begin{tabular}{|c||c|c|}
\hline \multicolumn{1}{|c|}{ name } & $\mathrm{Chemical}_{3}$ structure & $C: D$ \\
\hline \hline Caprylic-acid & $\mathrm{CH}_{3}\left(\mathrm{CH}_{2}\right)_{6} \mathrm{COOH}$ & $8: 0$ \\
\hline \hline Capric-acid & $\mathrm{CH}_{3}\left(\mathrm{CH}_{2}\right)_{8} \mathrm{COOH}$ & $10: 0$ \\
\hline \hline Lauric-acid & $\mathrm{CH}_{3}\left(\mathrm{CH}_{2}\right)_{10} \mathrm{COOH}$ & $12: 0$ \\
\hline \hline Myristic-acid & $\mathrm{CH}_{3}\left(\mathrm{CH}_{2}\right)_{12} \mathrm{COOH}$ & $14: 0$ \\
\hline \hline Palmitic-acid & $\mathrm{CH}_{3}\left(\mathrm{CH}_{2}\right)_{14} \mathrm{COOH}$ & $16: 0$ \\
\hline \hline Stearic-acid & $\mathrm{CH}_{3}\left(\mathrm{CH}_{2}\right)_{16} \mathrm{COOH}$ & $18: 0$ \\
\hline \hline Arachidic-acid & $\mathrm{CH}_{3}\left(\mathrm{CH}_{2}\right)_{18} \mathrm{COOH}$ & $20: 0$ \\
\hline \hline Behenic-acid & $\mathrm{CH}_{3}\left(\mathrm{CH}_{2}\right)_{20} \mathrm{COOH}$ & $22: 0$ \\
\hline \hline Lignoceric-acid & $\mathrm{CH}_{3}\left(\mathrm{CH}_{2}\right)_{22} \mathrm{COOH}$ & $24: 0$ \\
\hline Cerotic-acid & $\mathrm{CH}_{3}\left(\mathrm{CH}_{2}\right)_{24} \mathrm{COOH}$ & $26: 0$ \\
\hline
\end{tabular}

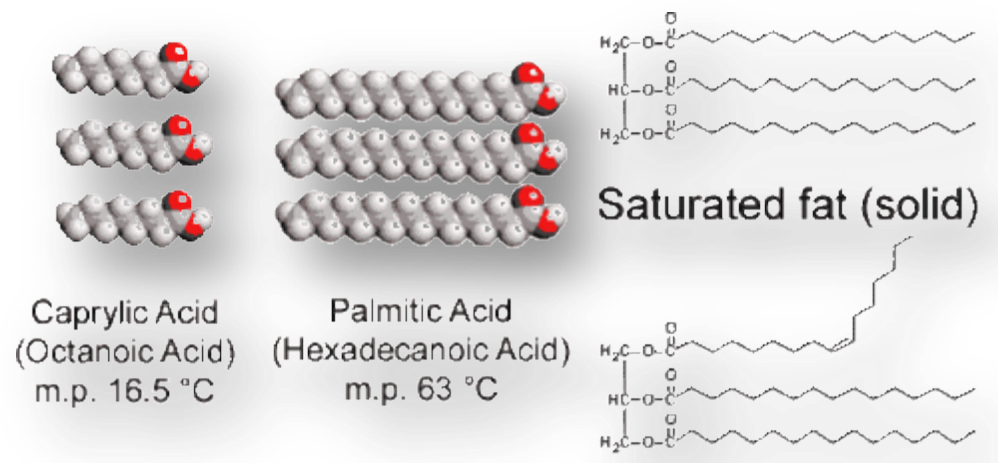

Unsaturated fat (liquid)

Picture1: Example of saturated and unsaturated fatty acids and their structure.

A saturated fat is a form of lipid, in which the fatty acids have single bonds. A fat is made up of two kinds of smaller molecules, which are mono-glyceride and fatty acids. Fats are made up of long chains of carbon atoms. Some carbon atoms are linked together by single bonds and others are linked by double bonds. Double bonds can react with hydrogen to become single bonds, so they are called saturated, because the second bond is broken up and each half of the bond is attached to a hydrogen atom. Animal fats mostly are saturated. The fats of plants and fish are unsaturated generally and the fat of fish are monounsaturated. ${ }^{2}$ Saturated fats tend to have higher melting points than their corresponding unsaturated fats which leads to the popular understanding that saturated fats tend to be solids at body temperatures, while unsaturated fats tend to be liquid oils. Various fats contain different proportions of saturated and unsaturated fat. Examples of foods which contain a high proportion of saturated fat, include animal fat products such as cream, cheese, butter, other whole milk, dairy products and fatty meats, which also contain dietary cholesterol. ${ }^{3}$ Certain vegetable products have high saturated fat content, such as coconut oil and palm kernel oil due to their place of growing that is tropical vents. ${ }^{4}$ Many prepared foods are high in saturated fat content, such as dairy, desserts and sausage. ${ }^{3,5}$ 


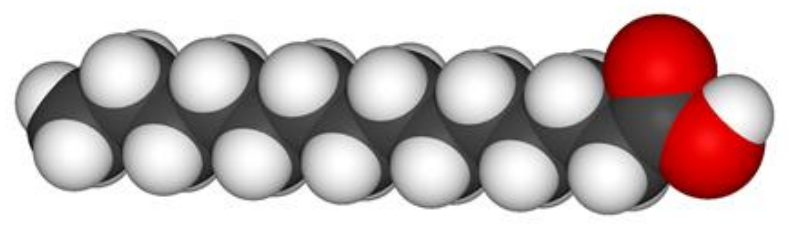

Picture2: Three dimensional structure of a saturated fatty acid

The effect of saturated fat on risk of heart disease is controversial. Many reviews recommend a diet low in saturated fat or fat as a whole, and argue it will lower risks of cardiovascular diseases, diabetes, or death. ${ }^{6}$ but other reviews have rejected those arguments or advocated for examining the proportion of saturated to unsaturated fat in the diet. ${ }^{7,8,9} \mathrm{~A}$ meta-analysis conducted in 2010 , conclusively showed that neither saturated fat nor dietary cholesterol cause harm in humans. ${ }^{10}$

\begin{tabular}{|c||c||c|c|c|}
\hline Food & Lauric acid & Myristic acid & Palmitic acid & Stearic acid \\
\hline \hline Coconut oil & $47 \%$ & $18 \%$ & $9 \%$ & $3 \%$ \\
\hline Palm kernel oil & $48 \%$ & $1 \%$ & $44 \%$ & $5 \%$ \\
\hline \hline Butter & $3 \%$ & $11 \%$ & $29 \%$ & $13 \%$ \\
\hline \hline Ground beef & $0 \%$ & $4 \%$ & $26 \%$ & $15 \%$ \\
\hline \hline Salmon & $0 \%$ & $1 \%$ & $29 \%$ & $3 \%$ \\
\hline \hline Egg yolks & $0 \%$ & $0.3 \%$ & $27 \%$ & $10 \%$ \\
\hline \hline Cashews & $2 \%$ & $1 \%$ & $10 \%$ & $7 \%$ \\
\hline \hline Soybean oil & $0 \%$ & $0 \%$ & $11 \%$ & $4 \%$ \\
\hline
\end{tabular}

Table2: Saturated fat profile of ordinary foods ${ }^{1}$

\subsection{Introduction to Lipid Hypothesis}

Lipid hypothesis theory says that: "there is a direct relationship between the amount of saturated fat and cholesterol in the diet and the incidence of coronary heart disease", which was proposed by a researcher named Ancel Keys in 1950's. Keys' researches received more publicity than those presenting alternate views. The vegetable oil and food processing companies began promoting and funding further research designed to support this hypothesis.

The researcher who made the low-fat diet well-known, named Nathan Pritikin. Although Nathan Pritikin advocated elimination of sugar, white flour and processed foods from the diet and recommended the use of fresh raw foods, whole grains, but it was the low-fat part of his regime which received the most attention. Adherents found that they lost weight and that their blood cholesterol levels and blood pressure declined. The success of the Pritikin diet was probably because of the number of factors having nothing to do with reduction in dietary fat and weight loss alone. For instance, it was believed that low-fat diet will precipitate a reduction in blood cholesterol levels, but Pritikin soon came to the conclusion that the fat-free diet presented many problems, not the least of which was the fact that people just could not stay on it. Those who possessed enough will power to remain fat-free for any length of time developed a variety of health problems including low energy, difficulty in concentration, depression, weight gain and 
mineral deficiencies. ${ }^{12}$ Pritikin might have saved himself from heart disease, but his low-fat diet did not save him from cancer. He passed away in the prime of life of suicide when he understood that his diet did not cure his leukemia.

When problems with the no-fat regime became apparent, Pritikin introduced a small amount of fat from vegetable sources into his diet, $10 \%$ of the total caloric intake. Nowadays, many researchers and nutritionists advise us to limit fats to $25-30 \%$ of the caloric intake, which is about 5 tablespoons per day for a diet of 2400 calories.

\section{Materials and Methods}

Surveying through many well published studies, and reviewing them carefully and prospectively, we collected many data and results for helping us conclude whether the consumption of saturated fat in the diet would be beneficial for human beings or industrialized vegetable oils or as a whole, unsaturated fats would be the best choice in reducing the incidence of heart disease. This research is the analysis of many studies and may help us with our future decision.

Before 1920, coronary heart disease was rare in the United States of America, so rare that when an internist named Paul Dudley White introduced the electrocardiograph to his colleagues at Harvard University, they advised him to concentrate on a more profitable branch of medicine. The new machine revealed the presence of arterial blockages, thus permitting early diagnosis of coronary heart disease. But in those days clogged arteries were a medical rarity, and White had to search for patients who could benefit from his new technology. During the next forty years, the incidence of coronary heart disease increased dramatically, so much that in the mid 50's, heart disease was the leading cause of death among Americans. Today heart disease causes at least $40 \%$ of all US deaths. From 1910 to 1970, the proportion of animal fat in the American diet declined from $83 \%$ to $62 \%$, and butter consumption decreased from $18 \mathrm{lbs}$ per person per year to $4 \mathrm{lbs}$. During the past 80 years, dietary cholesterol intake has increased only $1 \%$ and the percentage of dietary vegetable oils in the form of margarine and refined oils increased about $400 \%$, while the consumption of sugar and processed foods increased about $60 \% .^{13}$

The Framingham Heart Study began in 1948 and involved 6000 people from the town of Framingham, Massachusetts. Two groups were compared at five-year intervals. Those who consumed little cholesterol and saturated fat, and those who consumed large amounts. After 40 years, the result was astonishing: The more saturated fat, cholesterol, calories one takes, the lower the person's serum cholesterol becomes. They found that the people, who ate the most cholesterol and saturated fat, weighed the least and were mostly physically active. ${ }^{14}$ The study showed that those who weighed more and had abnormally high blood cholesterol levels were slightly more at risk for future heart disease, however, weight gain and cholesterol levels had an inverse correlation with fat and cholesterol intake in the diet. ${ }^{15}$ 


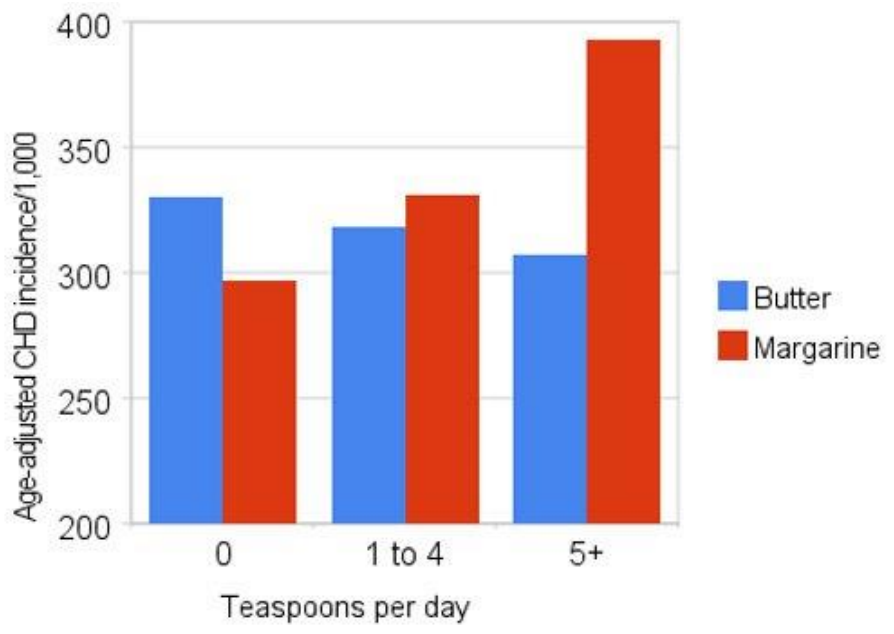

Picture3: In The Framingham Heart Study, Heart Disease incidence increases when People Replace Butter with Margarine. ${ }^{16}$

In a British study involving several thousand men, half were asked to reduce saturated fat and cholesterol in their diets, to stop smoking and to increase the amounts of unsaturated oils such as margarine and vegetable oils. After 360 days, those on the non-saturated fat diet had 100\% more deaths than those on the high saturated fat diet. ${ }^{17}$

In the United States Multiple Risk Factor Intervention Trial (MRFIT), the researchers compared mortality rates and eating habits of 12,000 men. Those with reduced saturated fat and cholesterol, showed a reduction in total coronary heart disease, but their overall mortality from other causes was higher. ${ }^{18}$

A study of 1700 patients with hardening of the arteries, conducted by the famous heart surgeon Michael De Bakey, which found no correlation between the level of cholesterol in the blood and the incidence of atherosclerosis. ${ }^{19}$

A survey of South Carolina adults found no correlation of blood cholesterol levels with the consumption of red meat, animal fats, butter, eggs, whole milk, and cheese. ${ }^{20}$

Medical Research Council study showed that men eating butter ran half the risk of developing heart disease as those using margarine. ${ }^{21}$

Human milk contains a lot higher proportion of cholesterol than any other food. It contains over $50 \%$ of its calories as fat with the type of saturated fat. Cholesterol and saturated fat are necessary for growth of the brain in infants and children. ${ }^{22}$ One study in 1995 linked low-fat diets with high mortality in children. ${ }^{23}$

The heart disease epidemic started approximately about 1930 and the obesity epidemic started in 1980 and ten years later the diabetes epidemic started around 1990. It is obvious from the graph below that mentioned diseases have increased dramatically as animal saturated fats have been replaced by margarine and processed vegetable oils (Stephan Guyenet et al. The American Diet, 2012). 


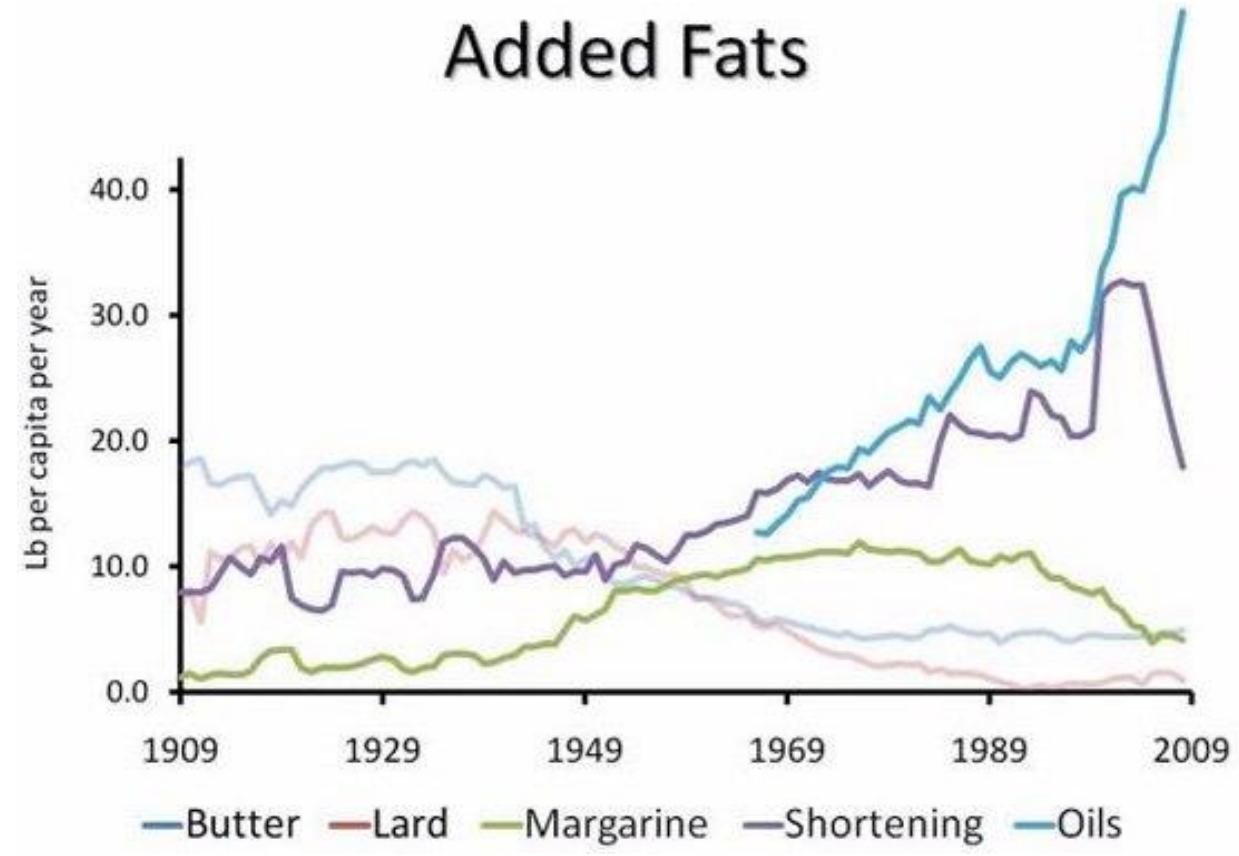

Picture4: Heart disease increased when the butter consumption decreased, and polyunsaturated fats in the form of vegetable oils increased.

\subsection{Native Tribes Diet, and the Incidence of Heart Disease}

A comparison of populations in northern and southern India showed that People in northern India consume 17 times more animal fat but have an incidence of coronary heart disease 7 times lower than people in southern India. ${ }^{24}$ The Masai tribe in Africa consume large amounts of milk and full-fat beef. They are free from coronary heart disease and have excellent blood cholesterol levels. ${ }^{25}$ Eskimos eat liberally of animal fats from fish and marine animals. On their native diet they are free of disease and exceptionally hardy ${ }^{26}$ One study in China found that the region in which the population consumes large amounts of whole milk had half the rate of heart disease as several districts in which only small amounts of animal products are consumed. ${ }^{27}$ Several Mediterranean societies have low rates of heart disease even though their dietary saturated fat is up to $70 \%$ of their caloric intake. The inhabitants of Crete are famous for their good health and longevity although their dietary consumption of fat is mostly saturated. ${ }^{28}$ A study of Puerto Ricans showed that, despite consuming large amounts of animal fat, they have a very low incidence of colon and breast cancer and heart diseases are low in them. ${ }^{29}$ A study of the inhabitants of Soviet Georgia revealed that those who eat the most full-fat meat, live the longest. ${ }^{30}$ In Okinawa, the average life span of women is 84 years which is longer than in Japan. The inhabitants eat high amounts of pork and seafood and cook their food in lard. ${ }^{31}$

Japanese eat few dairy fats, but their diet includes eggs, pork, chicken, beef, seafood and mostly organ meats. Since their diet is highly consisting of shellfish and fish broth on a daily basis, their intake of cholesterol is higher than most Americans. Since the World-war 2, the lifespan of Japanese increased dramatically due to their consumption of animal fat and protein and nonvegetable oils. ${ }^{32}$ Although the population in Switzerland lives almost as long on one of the 
fattiest diets in the world, they are the third in the longevity in statistics. Austria and Greece populations both live with high-fat diets. ${ }^{33}$

Although the French diet is high in saturated fats in the form of animal butter, eggs, cheese, fullfat cream, liver, meats and rich pates, but they have a lower rate of coronary heart disease than many other European countries. In the United States, 315 out of 100,000 middle-aged men die of heart attacks each year. In France the rate is 145 out of 100,000. In the Gascony region, where goose and duck liver form a staple of the diet, this rate is 80 out of $100,000 .^{34}$

\section{Conclusion}

Our choice of fats and oils is extremely important. Human beings, especially infants and growing children, need more fat in their diet. Therefore, the fats that we take should be chosen carefully. Processed foods containing hydrogenated fats and polyunsaturated oils should not be allowed in one's diet. Instead, consuming traditional vegetable oils like extra virgin olive oil and small amounts of unrefined flax seed oil is a rational choice. Saturated fats due to their stability in high temperature can be used for cooking. Eating egg yolks and other animal fats with the proteins to which they are attached is a wise choice. Good quality butter which contains vital fat soluble vitamins like A and $\mathrm{E}$ is necessary. Although it is believed that saturated fats cause heart disease, this research shows that these types of fats lead to decrease or even prevent coronary heart disease.

\section{Acknowledgements}

I would like to thank Mrs. Sally Fallon Morell, the president of Weston A. Price Foundation (WAPF) in Washington DC, Prof. Dominic D'Agostino and Prof. Thomas N. Seyfried for their help in preparing this article.

\section{References}

[1] Reece, Jane; Campbell, Neil (2002). Biology. San Francisco: Benjamin Cummings. Pp. 69-70. ISBN 0-8053-6624-5.

[2] Reece, Jane, Campbell, Neil (2002). Biology. San Francisco: Benjamin Cummings. Pp. 69-70. ISBN 0-8053-6624-5.

[3] Saturated fats. American Heart Association. 2014. Retrieved 1 March 2014.

[4] "What are oils?". ChooseMyPlate.gov, US Department of Agriculture. 2015. Retrieved 13 June 2015.

[5] Top food sources of saturated fat in the US. Harvard University School of Public Health. 2014. Retrieved 1 March 2014.

[6] Hooper L, Martin N, Abdel hamid A, Davey Smith G (2015). "Reduction in saturated fat intake for cardiovascular disease". Cochrane Database Syst Rev. 6 (Jun 10): CD011737. doi:10.1002/14651858.CD011737. PMID 26068959.

[7] de Souza, Russell J; Mente, Andrew; Maroleanu, Adriana; Cozma, Adrian I; Ha, Vanessa; Kishibe, Teruko; Uleryk, Elizabeth; Budylowski, Patrick; Schünemann, Holger; Beyene, Joseph; Anand, Sonia S (2015). "Intake of saturated and trans unsaturated fatty acids and risk of all cause mortality, cardiovascular disease, and type 2 diabetes: systematic review and meta-analysis of observational studies”. BMJ. 351 (Aug 11): h3978. doi:10.1136/bmj.h3978. PMC 4532752. PMID 26268692. 
[8] Ramsden, Christopher E; Zamora, Daisy; Leelarthaepin, Boonseng; Majchrzak-Hong, Sharon F; Faurot, Keturah R; Suchindran, Chirayath M; Ringel, Amit; Davis, John M; Hibbeln, Joseph R (2013). "Use of dietary linoleic acid for secondary prevention of coronary heart disease and death: evaluation of recovered data from the Sydney Diet Heart Study and updated metaanalysis". BMJ. 346. doi:10.1136/bmj.e8707.

[9] Ramsden, Christopher E; Zamora, Daisy; Majchrzak-Hong, Sharon; Faurot, Keturah R; Broste, Steven K; Frantz, Robert P; Davis, John M; Ringel, Amit; Suchindran, Chirayath M; Hibbeln, Joseph R (2016). "Re-evaluation of the traditional diet-heart hypothesis: analysis of recovered data from Minnesota Coronary Experiment (1968-73)”. BMJ. 353. doi:10.1136/bmj.i1246.

[10] Patty W Siri-Tarino, Qi Sun, Frank B Hu, and Ronald M Krauss. Meta-analysis of prospective cohort studies evaluating the association of saturated fat with cardiovascular disease. 2010 American Society for Nutrition.

[11] USDA National Nutrient Database for Standard Reference, Release 20. United States Department of Agriculture. 2007.

[12] Gittleman, Ann Louise, MS, Beyond Pritikin, 1980, Bantam Books, New York, NY.

[13] Enig, Mary G, PhD, Trans Fatty Acids in the Food Supply: A Comprehensive Report Covering 60 Years of Research, $2^{\text {nd }}$ Edition, Enig Associates, Inc, Silver Spring, MD, 1995, 4-8.

[14] Castelli, William, Arch Int Med, Jul 1992, 152:7:1371-1372.

[15] Hubert H, et al, Circulation, 1983, 67:968; Smith, R and E R Pinckney, Diet, Blood Cholesterol and Coronary Heart Disease: A Critical Review of the Literature, Vol 2, 1991, Vector Enterprises, Sherman Oaks, CA.

[16] $\mathrm{Hu} \mathrm{FB}$, et al. Trends in the Incidence of Coronary Heart Disease and Changes in Diet and Lifestyle in Women. The New England Journal of Medicine. 2000.

[17] Rose G, et al, Lancet, 1983, 1:1062-1065.

[18] "Multiple Risk Factor Intervention Trial; Risk Factor Changes and Mortality Results," JAMA, September 24, 1982, 248:12:1465.

[19] DeBakey, M, et al, JAMA, 1964, 189:655-59.

[20] Lackland, D T, et al, J Nutr, Nov 1990, 120:11S:1433-1436.

[21] Nutr Week, Mar 22, 1991, 21:12:2-3.

[22] Alfin-Slater, R B, and L Aftergood, "Lipids," Modern Nutrition in Health and Disease, $6^{\text {th }}$ ed, R S Goodhartand M E Shils, eds, Lea and Febiger, Philadelphia, 1980, 131.

[23] Smith, M M, and F Lifshitz, Pediatrics, Mar 1994, 93:3:438-443.

[24] Malhotra, S, Indian Journal of Industrial Medicine, 1968, 14:219.

[25] Kang-Jey Ho, et al, Archeological Pathology, 1971, 91:387; Mann, G V, et al, Am J Epidemiol, 1972, 95:26-37.

[26] Price, Weston, DDS, Nutrition and Physical Degeneration, 1945, Price-Pottenger Nutrition Foundation, San Diego, CA, 59-72.

[27] Chen, Junshi, Diet, Life-Style and Mortality in China: A Study of the Characteristics of 65 Chinese Counties, Cornell University Press, Ithica, NY.

[28] Willett, W C, et al, Am J Clin Nutr, June 1995, 61(6S):1402S - 1406S; Perez-Llamas, F, et al, J Hum Nutr Diet, Dec 1996, 9:6:463-471; Alberti-Fidanza, A, et al, Eur J Clin Nutr, Feb 1994, 48:2:85-91.

[29] Fernandez, N A, Cancer Res, 1975, 35:3272; Martines, I, et al, Cancer Res, 1975, 35:3265.

[30] Pitskhelauri, G Z, The Long Living of Soviet Georgia, 1982, Human Sciences Press, New York, NY.

[31] Franklyn, D, Health, September 1996, 57-63.

[32] Koga, Y et al, "Recent Trends in Cardiovascular Disease and Risk Factors in the Seven Countries Study: Japan," Lessons for Science from the Seven Countries Study, H Toshima, et al, eds, Springer, New York, NY, 1994, 63-74. 
[Niknamian et. al., Vol.5 (Iss.1): January, 2017]

ICV (Index Copernicus Value) 2015: 71.21
ISSN- 2350-0530(O), ISSN- 2394-3629(P) IF: 4.321 (CosmosImpactFactor), 2.532 (I2OR) InfoBase Index IBI Factor 3.86

[33] Moore, Thomas J, Lifespan: What Really Affects Human Longevity, 1990, Simon and Schuster, New York, NY.

[34] O’Neill, Molly, NY Times, Nov 17, 1991.

*Corresponding author.

E-mail address: Saina.monthly@gmail.com 